OPEN ACCESS

Edited by:

Hermann Eibel,

University of Freiburg Medical Center,

Germany

Reviewed by:

Christian Kosan,

Friedrich Schiller University Jena,

Germany

Stéphane J. C. Mancini, INSERM U1068 Centre de Recherche en Cancérologie de Marseille (CRCM),

France

*Correspondence:

Christelle Vincent-Fabert christelle.vincent-fabert@unilim.fr

Specialty section:

This article was submitted to B Cell Biology,

a section of the journal

Frontiers in Immunology

Received: 19 February 2021 Accepted: 11 May 2021

Published: 25 May 2021

Citation:

Lemasson Q, Akil H, Feuillard J and Vincent-Fabert C (2021) Genetically Engineered Mouse Models Support a

Major Role of Immune CheckpointDependent Immunosurveillance Escape in B-Cell Lymphomas.

Front. Immunol. 12:669964. doi: 10.3389/fimmu.2021.669964

\section{Genetically Engineered Mouse Models Support a Major Role of Immune Checkpoint-Dependent Immunosurveillance Escape in B-Cell Lymphomas}

\author{
Quentin Lemasson ${ }^{1,2}$, Hussein Akil ${ }^{1,2}$, Jean Feuillard ${ }^{1,2}$ and Christelle Vincent-Fabert ${ }^{1,2 *}$ \\ 1 UMR CNRS 7276/INSERM U1262 CRIBL, University of Limoges, Limoges, France, ${ }^{2}$ Hematology Laboratory of Dupuytren \\ Hospital University Center (CHU) of Limoges, Limoges, France
}

These last 20 years, research on immune tumor microenvironment led to identify some critical recurrent mechanisms used in cancer to escape immune response. Through immune checkpoints, which are cell surface molecules involved in the immune system control, it is now established that tumor cells are able to shutdown the immune response. Due to the complexity and heterogeneity of Non Hodgkin B-cell Lymphomas (NHBLs), it is difficult to understand the precise mechanisms of immune escape and to explain the mitigated effect of immune checkpoints blockade for their treatment. Because genetically engineered mouse models are very reliable tools to improve our understanding of molecular mechanisms involved in B-cell transformation and, at the same time, can be useful preclinical models to predict immune response, we reviewed hereafter some of these models that highlight the immune escape mechanisms of NHBLs and open perspectives on future therapies.

Keywords: B-cell lymphoma, immune surveillance, PD-1/PD-L1, CTLA-4, MHC-II, NKG2D

\section{INTRODUCTION}

Non Hodgkin B-cell Lymphomas (NHBLs) are malignant neoplasms characterized by an abnormal expansion of clonal B lymphocytes. Despite being subdivided in more than 50 entities (1), most of them can be ascribed as indolent (low grade) or aggressive forms (high grade). Immune escape, also called immunomodulation or immunoediting, is a way by which tumors neutralize and/or subvert the host's immune system to their advantage (2). The concept of host immune response against neoantigens has been demonstrated long time ago (3) and Tumor Infiltrated Lymphocytes (TILs) have been recognized very early as a biomarker of the immune response against cancer (4). However, tumor cells are able to evade immune response by developing an immunosuppressive microenvironment through the regulation of immune checkpoint protein expression, such proteins being essential in the negative control of activated immune cells. Various immunotherapy treatments aim to reactivate antitumor immune response by targeting specific immune-checkpoint proteins (5). Programmed cell-Death 1 (PD-1) and its ligand Programmed cell-Death Ligand 1 (PDL1) are the most studied immune checkpoint proteins. If immune restoring therapies have given 
spectacular results in some solid cancers such as those of the lung, colon or melanoma, effects on B-cell lymphomas are mitigated (6). There is an urgent need to understand how tumor B cells escape immune surveillance. Thanks to genetic engineering, mouse models are globally useful for phenocopying human B-cell lymphomas and investigating the emergence and progression of transformed B cells as well as their concomitant immune escape and for researching new therapeutic strategies.

Here, we discuss different mouse models that have been used to study the B-cell immune surveillance (Figure $\mathbf{1}$ and Table 1). The human relevance of these models is first presented, and then, the experimental results are summarized and discussed. A large part of studies presented hereafter investigated the PD-1/PD-L1 axis. However, other molecules such as CTLA-4, MHC-II or NKG2D are discussed. Strikingly, these models provide functional clues to genetic abnormalities as well as immune evasion occurring in B-cell lymphomas, and recurrently highlight the role of $\mathrm{NF}-\kappa \mathrm{B}$. Indeed, as reviewed recently, $\mathrm{NF}-\kappa \mathrm{B}$ plays a major role in immune checkpoint controls and directly regulates PD-L1 expression (17).

\section{DEREGULATION OF PD-1/PD-L1 AXIS IN MOUSE MODELS OF B-CELL LYMPHOMAS}

Discovered in the nineties, $\mathrm{PD}-1$ and $\mathrm{PD}-\mathrm{L} 1$ remain the most promising immune checkpoint targets for cancer immunotherapy
(18, 19). PD-L1 (B7-H1 or CD274) binds to its receptor PD-1 (CD279) on T cells (20). PD-L1 first promotes naïve T-cell expansion through IL-10 stimulation (19). Then, PD-1/PD-L1 signaling induces effective inhibition/exhaustion of $\mathrm{T}$ cells in the context of chronic antigen stimulation (20). Among effects, PD1/PD-L1 interaction leads to a drastic inhibition of the T-cell receptor (TCR) signaling as well as AKT, ERK and NF- $\kappa B$ signaling pathways. Essential for the immune response control, this mechanism is adopted by tumor cells to escape immune surveillance. PD-L1 expression by tumor B cells has been found in various lymphoma subtypes such as Diffuse Large B-Cell Lymphomas (DLBCL), associated or not with the Epstein Barr virus (EBV). This tumor phenotype is usually associated with an intratumoral infiltration of $\mathrm{PD}^{+}{ }^{+} \mathrm{T}$-lymphocytes (PD1 ${ }^{+} \mathrm{TILs)}$ $(21,22)$, thus exhibiting an inflamed phenotype according to classification of Chen (23). The selection pressure exerted by the immune surveillance is probably one of the drivers of the emergence of B-cell clones since chromosomal alterations in the 9p24.1 region which harbors the PDL1 and PDL2 loci are found in most classical Hodgkin lymphomas (HL) as well as in $27 \%$ of non Germinal Center B (GCB) DLBCLs, both B-cell cancers strongly associated with NF- $\kappa B$ activation (24). AntiPD-1/PD-L1 therapy has given promising results in HL (25). PD-L1 expression is found in 26-75\% (26) of patients with higher expression in Activated B-Cell (ABC) DLBCL, presumably due to the constitutively activated NF- $\kappa B$ as it is in Epstein Barr Virus (EBV)-positive DLBCL (27). However, correlation between PD-L1 expression and the response to PD-1/PD-L1 therapy in DLBCLs remains controversial (28).

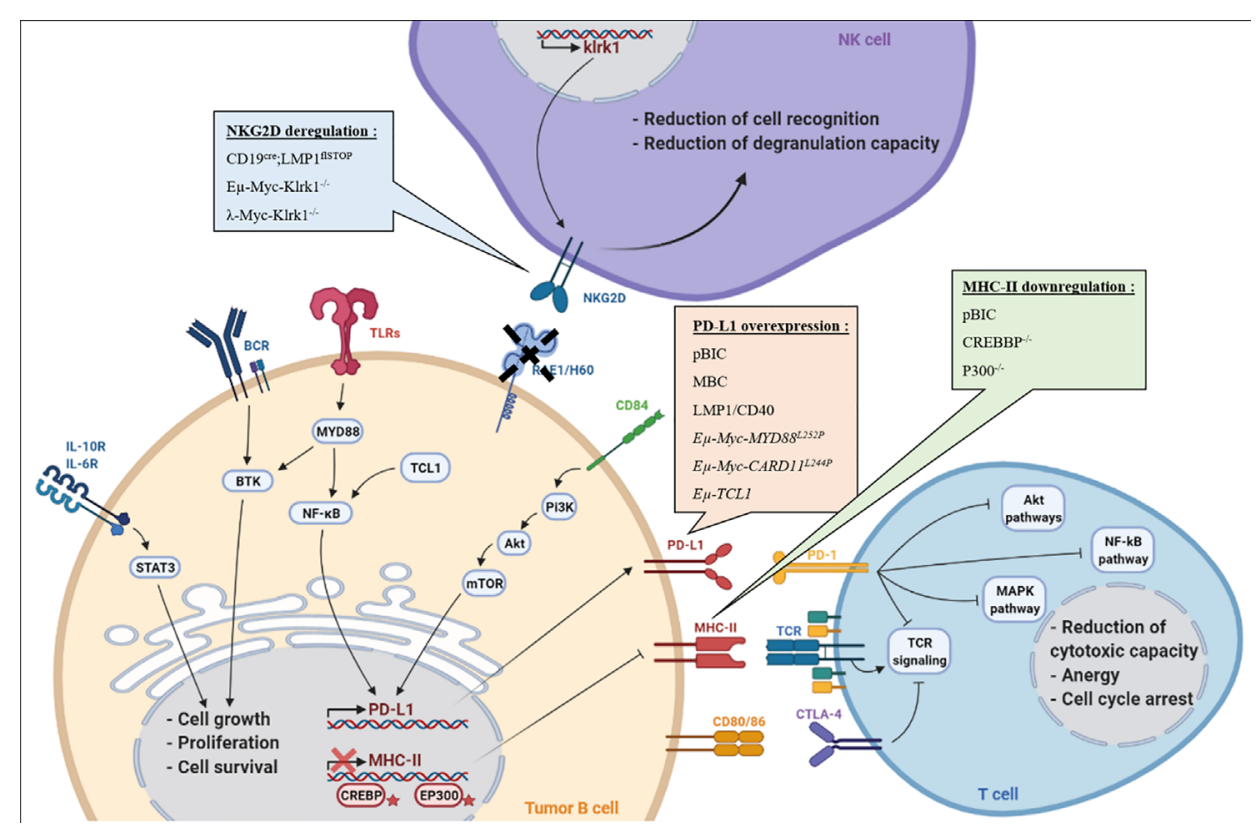

FIGURE 1 | B/T/NK cells in the immune escape context. Representation of different mechanisms exploited by tumor B-cell lymphomas to escape immune control during lymphomagenesis in each presented transgenic mouse models: (i) overexpression of PD-L1 associated with MHC-II downregulation to induce T-cell anergy, (ii) Reduction of RAE1/H60 expression to induce NK cells tolerance, (iii) CTLA-4 expressed by T-cells is targeted by lymphoma B cells, leading to T-cell inactivation. 
TABLE 1 | Transgenic mouse models.

\begin{tabular}{|c|c|c|c|c|c|}
\hline Model & Strategy & Expression/Induction & Phenocopy & Immune escape strategy & Reference \\
\hline \multicolumn{6}{|c|}{ CRE regulated expression } \\
\hline $\mathrm{pBIC}$ & $\begin{array}{l}\text { NF- } \kappa \mathrm{B} \text { constitutive signaling } \\
\text { Blimp1 inactivation } \\
\text { p53 inactivation }\end{array}$ & $\begin{array}{l}\text { GC-B cell compartment } \\
\left(\left.\mathrm{C} \gamma\right|^{\mathrm{CRE}}\right)\end{array}$ & ABC-DLBCL & $\begin{array}{l}\text { PD-L1 overexpression } \\
\text { MHC-II downregulation }\end{array}$ & (7) \\
\hline MBC & $\begin{array}{l}\text { endogenous MYD88 } \\
\text { expression } \\
\text { BCL2 overexpression }\end{array}$ & $\begin{array}{l}\text { B-cell compartment } \\
\left(\text { Cd19 }{ }^{\mathrm{CRE}}\right)\end{array}$ & ABC-DLBCL & PD-L1 overexpression & (8) \\
\hline $\mathrm{CREBBP}^{-/-}$ & CREBBP inactivation & $\begin{array}{l}\text { GC-B cell compartment } \\
\left(\text { AID }^{\text {CRE }}\right)\end{array}$ & DLBCL & MHC-II deregulation & (9) \\
\hline $\mathrm{P} 300^{-/-}$ & p300 inactivation & $\begin{array}{l}\text { GC-B cell compartment } \\
\left(\text { AID }^{\text {CRE }}\right)\end{array}$ & DLBCL & MHC-II deregulation & (9) \\
\hline CD19 ${ }^{\text {cre }} ;$ LMP $1^{\text {fISTOP }}$ & EBV's LMP1 expression & $\begin{array}{l}\text { B-cell compartment } \\
\left.\text { (Cd19 }{ }^{\mathrm{CRE}}\right)\end{array}$ & EBV driven lymphomas & NKG2D blocking & $(10)$ \\
\hline LMP1/CD40 & CD40 constitutive signaling & $\begin{array}{l}\text { B-cell compartment } \\
\text { (Cd19 }\end{array}$ & SMZL & PD-L1 overexpression & $(11)$ \\
\hline \multicolumn{6}{|c|}{$\mathrm{E} \mu \mathrm{Myc} / \lambda \mathrm{Myc}$ regulated expression } \\
\hline E $\mu-M y c-M Y D 88^{L 252 P}$ & transplantation of $\mathrm{E} \mu-M y c-M Y D 88^{\mathrm{L} 252 \mathrm{P}}$ & B cell lineage & ABC-DLBCL & PD-L1/PD-L2 overexpression & $(12)$ \\
\hline E $\mu-M y c-C A R D 11^{L 244 P}$ & transplantation of $\mathrm{E} \mu-M y c-C A R D 11^{\mathrm{L} 244 \mathrm{P}} \mathrm{HSCs}$ & B cell lineage & ABC-DLBCL & PD-L1/PD-L2 overexpression & $(12)$ \\
\hline hCTLA4-FC $\gamma R^{-/-}$ & $\begin{array}{l}\text { Human CTLA4 expression } \\
\text { FcyR inactivation }\end{array}$ & B cell lineage & CLL & CTLA4 deregulation & (13) \\
\hline E $\mu-M y c-K I r k 1^{-/-}$ & NKG2D inactivation & B cell lineage & MYC driven lymphomas & Absence of NKG2D & $(14)$ \\
\hline$\lambda$-Myc-Klrk1-/- & NKG2D inactivation & B cell lineage & $\mathrm{BL}$ & Absence of NKG2D & $(15)$ \\
\hline $\mathrm{E} \mu-\mathrm{TCL} 1$ & TCL1 overexpression & B cell lineage & CLL & PD-L1/PD-L2 overexpression & $(16)$ \\
\hline
\end{tabular}

(ABC-)DLBCL, (Activated B-Cell) Diffuse Large B-Cell Lymphoma; EBV, Epstein Barr Virus; SMZL, Splenic Marginal Zone Lymphoma; CLL, Chronic Lymphocytic Leukemia; $B L$, Burkitt Lymphoma.

Recently, two studies dealing with NF- $\mathrm{KB}$ associated DLBCLs showed similar results. The first one used the MBC model, developed by Knittel et al., which develop aggressive DLBCLlike tumors (29). These mice harbor the MYD8 $8^{\mathrm{L} 252 \mathrm{P}}$ mutation and overexpress the anti-apoptotic factor BCL2, two features found in $29 \%$ and $40 \%$ of ABC-DLBCL cases respectively (30, 31). Flümann et al. found a striking resemblance of $\mathrm{MBC}$ tumors with human ABC-DLBCLs, with a similar gene expression profile (8). They also demonstrated overexpression of Pdl1 on MBC lymphoma B cells associated with exhausted infiltrating $\mathrm{CD}^{+}$and $\mathrm{CD}^{+} \mathrm{T}$ cells, highlighting the immune escape strategy used by tumor cells.

In the second study, Reimann et al. engineered an original ABC-DLBCL model based on the demonstrated cooperation between c-MYC and NF- $\mathrm{KB}$ (32). Hematopoietic Stem Cells (HSC) from $\mathrm{E} \mu-M y c$ mice were stably transduced with naturally occurring NF- $\mathrm{KB}$ mutants, among them MYD88 ${ }^{\mathrm{L} 252 \mathrm{P}}$ or CARD11 ${ }^{\mathrm{L} 244 \mathrm{P}}$. Transduced $\mathrm{E} \mu-M y c$ cells were injected into lethally irradiated strain-matched C57BL/6 recipients. All these allograft models supported MYC-driven B-cell lymphomagenesis through increased protection against apoptosis, but only MYD88 ${ }^{\mathrm{L} 252 \mathrm{P}}$ or CARD11 ${ }^{\mathrm{L} 244 \mathrm{P}} \mathrm{E} \mu-M y c$ tumors resembled to human ABC-DLBCL, including expression of PD-L1 which was responsible for an exhausted T-cell phenotype (12).

In both studies, the authors treated their mouse model with anti-PD-1 antibodies, leading to a significant increase in overall mouse survival and inducing phenotypic changes in infiltrating $\mathrm{CD}^{+}$and $\mathrm{CD}^{+} \mathrm{T}$ cells with a restored proliferation potential. The combination of anti-PD-1 antibody and BCL2 inhibitor showed an additive effect in the MBC model. The anti-PD-1 treatment seems to be really effective regarding these models. But recent human clinical trial showed a completely different reality (6), raising the question of resistance to these therapies. Some clues may have been given by the pBIC model. This model associates Tp53 deletion, enhanced NF- $\mathrm{KB}$ signaling due to an activated IKK2 mutant, and Blimp1 inactivation that blocks plasma-cell differentiation. Pascual et al. showed that, in these mice, DLBCL-like tumors exhibited an ABC-DLBCL phenotype with FOXP1 dysregulation and overexpression of PD-L1 by tumor cells. This phenotype was associated with intra-tumor infiltration of $\mathrm{PD}-1^{+} \mathrm{CD} 8^{+} \mathrm{T}$ cells. Exhibiting an exhausted phenotype, these TILs also expressed other inhibitory molecules such as LAG-3 and 2B4 (7). In this model, anti-PD1 treatment did not show any effect on mouse survival and antiCD20 treatment alone had limited impact. But combining both antibodies markedly improved mouse survival and resulted in tumor regression with clearance of PD-1 TILs, strongly suggesting that therapies targeting the PD1/PD-L1 axis could be used in combination with other well established treatments in DLBCLs.

Taken together, these different mouse models for ABC-DLBCLs suggest that $\mathrm{PD}-1 / \mathrm{PD}-\mathrm{L} 1$ immune checkpoint upregulation is one of the main mechanisms of immunosurveillance escape in ABCDLBCL. It also indicates that, even when poorly effective alone, anti PD-1/PD-L1 therapies may very well be able to improve the effect of other molecules that directly target tumor B cells.

To our knowledge, only four mouse models of indolent B-cell lymphoma have been reported. One is related to Chronic Lymphocytic Leukemia (CLL) with TCL1 (originally described in the former CD4 T-CLL, now called T-cell prolymphocytic leukemia) as a driver oncogene (33) and three others to marginal 
zone lymphomas, involving Traf3 deletion (34), BCL10 deregulation (35) and CD40 signaling (11). The question of immune surveillance was addressed only in the TCL1 and CD40 mouse models. First, Hofbauher et al. demonstrated that development of a CLL-like disease was associated with a shift from naive to memory phenotypes of both $\mathrm{CD}^{+}$and $\mathrm{CD} 8^{+} \mathrm{T}$ cells in E $\mu$-TCL1 transgenic mice (16). In the context of aging, McClanahan et al. described in this model a PD-1 overexpression on $\mathrm{CD}^{+} \mathrm{T}$ cells with a defect in immune synapse formation, associated with specific PD-L1 overexpression on B cells (36). In the same model, Lewinsky et al. demonstrated the role of CD84, a member of the Signaling Lymphocyte Activating Molecule (SLAM) family known to bridge between CLL cells and their microenvironment (37). CD84 (SLAMF5) activation upregulates PD-L1 expression on CLL cells and stroma cells, through the AKT/mTOR pathway, and promotes PD-1 expression on T cells resulting in their exhaustion (38). In an adoptive transfer of $\mathrm{E} \mu$ TCL1 CLLs, PD-L1 blockade restored the antitumor immune response, in conjunction with an enhanced pro-inflammatory microenvironment (39). However, the question of the tumor microenvironment arises with this strategy. Adoptive transfer of $\mathrm{E} \mu$-TCL1 leukemic cells proves their ability to invade and proliferate in a healthy microenvironment by their own, but this development is independent of the tumor microenvironment, and consequently a real immune escape mechanism remains hard to identify here.

Being also associated with NF- $\mathrm{\kappa B}$ activating mutations, splenic marginal zone lymphomas exhibit an inflamed phenotype $(40,41)$. In the model of Hömig-Hözel et al., B-cell specific continuous CD40 signaling is due to specific B-cell expression of a chimeric LMP1/CD40 protein composed of the membrane moiety of the LMP1 protein of EBV and the intracytoplasmic transducing moiety of CD40 (11). LMP1/ CD40 mice develop indolent lymphomas with clonal expansion of spleen marginal zone B cells. The indolent phenotype was shown to be associated with an overexpression of PD-L1 on B cells, such expression depending on NF- $\kappa B$, STAT3 and BCR pathways (42). In this model, T-cell depletion resulted in progression toward an aggressive tumor, suggesting that some immune surveillance was still exerted on indolent Bcell lymphoma (43). Indeed, crossing the LMP1/CD40 and $\lambda$ $-M y c$ mice (in which $M y c$ is under the control of the Ig lambda locus) led to the development of aggressive B-cell tumors with an immunoblast phenotype and further PD-L1 expression (32). This study suggests that the PD-1/PD-L1 axis is requested for emergence of an indolent lymphoma as well as for its progression towards an aggressive form. Concomitantly, our group demonstrated a beneficial effect of anti-PD-L1 therapy in the LMP1/CD40 model, resulting in tumor regression and T-cell reactivation. Interestingly, we also demonstrated that therapies targeting other pathways, such as NF- $\mathrm{KB}$, JAK/STAT or BCR signaling, were also able to reduce PD-L1 surface expression of tumor B cells (42). Like in mouse DLBCL models, these results suggest that, as long as they are expressed, PD-1 and/or PD-L1 blockade in indolent B-cell lymphomas may synergize with other therapeutic molecules, for example, the specific inhibitors of JAK/STAT pathway, ruxolitinib, or, of BTK, ibrutinib.
In essence, these different transgenic mouse models highlight the major role of PD-1/PD-L1 axis deregulation in aggressive lymphomas development, but also showed the involvement of this immune checkpoint in the transformation of indolent lymphomas as long as they express PD-L1. They also indicate that the level of PD-L1 expression may be a critical parameter for immune evasion and tumor progression and point on the interest of combined therapies that include anti-tumor immune restoration.

\section{DEREGULATION OF OTHER IMMUNE CHECKPOINTS IN MOUSE MODELS OF B-CELL LYMPHOMAS}

\section{CTLA-4}

In Humans, a single nucleotide polymorphism located in the $3 q 13.33$ region that harbors the CD80 and CD86 loci is associated with the risk of DLBCL, providing evidence for the role of immune function in the etiology of these lymphomas (44). The activating effects of CD80 and CD86 on CD28 are neutralized by the Cytotoxic T-Lymphocyte Antigen 4 (CTLA4). CTLA-4, normally expressed on the surface of activated and regulatory T cells as well as B cells, even if weakly, is the second major immune checkpoint molecule. As CTLA-4 has a higher affinity to $\mathrm{CD} 28$ than for $\mathrm{CD} 80$ or $\mathrm{CD} 86$, it downregulates primary $\mathrm{T}$-cell responses by interaction with $\mathrm{B} 7$ family members expressed on Antigen Presenting Cells (APCs) (45). CTLA-4 was shown to be abnormally expressed on B-cell lymphomas, and is notably a part of the CLL signature (46).

In the E $\mu$-TCL1 mouse model, CTLA-4, which is expressed on CLL-like B cells, seems to promote STAT3 activation pathway through its dimerization with surface CD86 followed by its internalization, and thus acting as a costimulatory signal (47). By using the adoptive transfer strategy, Do et al. showed that specific CTLA4 blockade on tumor cells could affect leukemic progression (13).

\section{MHC-II}

Besides their direct role in antibody secretion, B cells express MHC-II and are also APCs. B-cells are able to improve T-cell activation and proliferation through a process called $\mathrm{B} / \mathrm{T}$-cell cooperation $(48,49)$. In B cell lymphomas, loss of MHC-II contributes to the immune evasion resulting in a decrease of T-cell activity. This loss of surface MHC-II may be due to genetic alterations of the MHC-II region, including homozygous deletions (50). Malignant B cells can also downregulate the expression of MHC-II by various mechanisms $(7,9,51)$ such as the downregulation of the MHC-II transcriptional activators class II transactivator (CIITA). The consequence of MHC-II down-regulation in tumor B-cell escape has been exemplified in two KO models for the Histone Acetyl-Transferases (HAT) Crebbp or Ep300 (which deletions are found in $50 \%$ of human DLBCLs). In these models, development of aggressive B-cell tumors was related to the fact that $\mathrm{CD} 4^{+} \mathrm{T}$ cells were unable to interact with $\mathrm{B}$ cells because the latter had lost the expression of MHC-II which is normally up-regulated by these HAT (9). 
In addition, loss of MHC-II was also demonstrated in the pBIC mouse lymphoma model, suggesting a cooperation with the PD1/PD-L1 in immunosurveillance escape (7). If there is no current treatment allowing a direct restoration of MHC-II at the surface of tumor cells, McClanahan et al. showed a restoration of MHCII surface expression after anti-PD-L1 treatment in the CLL model E $\mu$-TCL1 (39).

Thereby, studies on $\mathrm{pBIC}$ and $\mathrm{E} \mu$-TCL1 models converge to show a striking correlation between PD-L1 and MHC-II deregulation in different types of lymphomas. Nevertheless, these findings deserve to be more closely investigated to improve the comprehension of immune checkpoints deregulation in lymphomas.

\section{NKG2D}

In Humans, cells infected by the EBV are under powerful immune surveillance by $\mathrm{T}$ and $\mathrm{NK}$ cells. Compromising this immune surveillance such as in AIDS or after organ transplantation, results in aggressive EBV-related B-cell lymphoproliferations. NK-cell functions could strongly be altered in DLBCLs that can be associated with resistance to rituximab-based therapies (52). Mouse Natural Killer Group 2 member D (NKG2D) is a receptor expressed by all cytotoxic lymphocytes, notably NK cells, activated $\mathrm{CD}^{+} \mathrm{T}$ cells and activated macrophages (53). Two murine NKG2D ligands have been described (RAE-1 and H60) (53-56). Interaction between NKG2D and its ligands induces PI3K-AKT signaling, leading to an increase in target recognition, cytotoxic activity and a reduction in sensitivity to cell apoptosis (57). NKG2D ligands are normally expressed at the surface of any virally infected/ tumorigenic cells. Both mouse and human studies suggest that tumor cells evade NKG2D recognition either by downregulating NKG2D ligands expression $(14,58)$ or by secreting massively circulating NKG2D ligands resulting in a downregulation of NKG2D expression on cytotoxic cells (59-61). The occurrence of B-cell lymphomas is accelerated in the absence of NKG2D. In mice, Guerra et al. showed, in 2008, that the deletion of Klrk1, the gene encoding NKG2D, in $\mathrm{E} \mu-M y c$ mice, accelerates the emergence of $\mathrm{E} \mu-M y c$-induced lymphomas (14). A similar effect was shown on an EBV dependent mouse B-cell lymphoma (10), and also in a BL $\lambda$-Myc-Klrk1 ${ }^{-1-}$ mouse model (15). Belting et al. completed this observation by demonstrating the role of NKG2D in the control of B-cell lymphoma growth and observed another escape mechanism developed by lymphomas cells through downregulating NKG2DL during the NK cell activation through downregulating NKG2DL (15).

All these different studies demonstrate the importance to escape the recognition of NKG2D receptor in B-cell lymphomagenesis and suggest its implication in the aggressive phenotype of these diseases.

\section{REFERENCES}

1. Swerdlow SH, Campo E, Pileri SA, Harris NL, Stein H, Siebert R, et al. The 2016 Revision of the World Health Organization Classification of Lymphoid Neoplasms. Blood (2016) 127(20):2375-90. doi: 10.1182/blood-2016-01643569

\section{CONCLUSION}

The pressure of the immune surveillance is certainly one of the major driving forces in the emergence of B-cell lymphomas. Together, results reported in the articles reviewed here, support the fact that mouse models are useful to analytically understand the immune escape in both aggressive and indolent B-cell lymphomas. Beyond PD-1/PD-L1 axis, roles of CTLA-4, of antigen presentation and of NK-cells is also highlighted. These models functionally explain and resume the role of the different actors of the immune surveillance in B-cell lymphomas. Engineered mouse models will contribute to better understand tumor microenvironment in the aim to identify novel mechanisms of B-cell immune escape, which may be the keystone of future therapies. Mouse models are also useful for the preclinical study of these therapies, evidencing the interest of combinations that include treatments able to restore the antitumor immune response. All the models presented here point out the major role of $\mathrm{NF}-\kappa \mathrm{B}$ activation, suggesting that this pathway should also be targeted together with immune restoration therapies. Before trying such strategies in Humans, this is testable in genetically engineered mouse models. Providing a strong support for the issue of immune escape in B-cell lymphomas, these models deserve to be widely used.

\section{AUTHOR CONTRIBUTIONS}

All authors contributed to the article and approved the submitted version. QL performed the literature review and prepared the figure and table. QL, HA, JF, and CVF wrote the manuscript.

\section{FUNDING}

The group of JF is supported by grants from the Ligue Nationale Contre le Cancer (Equipe labellisée Ligue), the Comite Orientation Recherche Cancer (CORC), the France Lymphome Espoir association, the Nouvelle Aquitaine Region and the HauteVienne and Corrèze committees of the Ligue Nationale Contre le Cancer. CVF was supported by the France Lymphome Espoir association of patients. QL was supported by the Fondation pour la Recherche Médicale (FRM, ECO202006011493).

\section{ACKNOWLEDGMENTS}

We thank Dr Jeanne Cook Moreau (UMR CNRS 7276/INSERM 1262) for careful English editing.

2. Menter T, Tzankov A. Mechanisms of Immune Evasion and Immune Modulation by Lymphoma Cells. Front Oncol (2018) 8:54. doi: 10.3389/ fonc.2018.00054

3. Wortzel RD, Philipps C, Schreiber H. Multiple Tumour-Specific Antigens Expressed on a Single Tumour Cell. Nature (1983) 304(5922):165-7. doi: $10.1038 / 304165 \mathrm{a} 0$ 
4. Vose BM, Moore M. Human Tumor-Infiltrating Lymphocytes: A Marker of Host Response. Semin Hematol (1985) 22(1):27-40.

5. Witkowska M, Smolewski P. Immune Checkpoint Inhibitors to Treat Malignant Lymphomas. J Immunol Res (2018) 2018:1982423. doi: 10.1155/ 2018/1982423

6. Ansell SM, Minnema MC, Johnson P, Timmerman JM, Armand P, Shipp MA, et al. Nivolumab for Relapsed/Refractory Diffuse Large B-Cell Lymphoma in Patients Ineligible for or Having Failed Autologous Transplantation: A Single-Arm, Phase II Study. J Clin Oncol Off J Am Soc Clin Oncol (2019) 37(6):481-9. doi: 10.1200/JCO.18.00766

7. Pascual M, Mena-Varas M, Robles EF, Garcia-Barchino M-J, Panizo C, Hervas-Stubbs S, et al. PD-1/PD-L1 Immune Checkpoint and p53 Loss Facilitate Tumor Progression in Activated B-cell Diffuse Large B-cell Lymphomas. Blood (2019) 133(22):2401-12. doi: 10.1182/blood.2018889931

8. Flümann R, Rehkämper T, Nieper P, Pfeiffer P, Holzem A, Klein S, et al. An Autochthonous Mouse Model of Myd88- and BCL2-Driven Diffuse Large B-Cell Lymphoma Reveals Actionable Molecular Vulnerabilities. Blood Cancer Discov (2020) 2:70-91. doi: 10.1158/2643-3230.BCD-19-0059

9. Hashwah H, Schmid CA, Kasser S, Bertram K, Stelling A, Manz MG, et al. Inactivation of CREBBP Expands the Germinal Center B Cell Compartment, Down-Regulates MHCII Expression and Promotes DLBCL Growth. Proc Natl Acad Sci USA (2017) 114(36):9701-6. doi: 10.1073/pnas.1619555114

10. Zhang B, Kracker S, Yasuda T, Casola S, Vanneman M, Hömig-Hölzel C, et al. Immune Surveillance and Therapy of Lymphomas Driven by Epstein-Barr -Virus Protein LMP1 in a Mouse Model. Cell (2012) 148(4):739-51. doi: 10.1016/j.cell.2011.12.031

11. Hömig-Hölzel C, Hojer C, Rastelli J, Casola S, Strobl LJ, Müller W, et al. Constitutive CD40 Signaling in B Cells Selectively Activates the Noncanonical NF- KB Pathway and Promotes Lymphomagenesis. J Exp Med (2008) 205 (6):1317-29. doi: $10.1084 /$ jem.20080238

12. Reimann M, Schrezenmeier JF, Richter-Pechanska P, Dolnik A, Hick TP, Schleich K, et al. Adaptive T-cell Immunity Controls Senescence-Prone MyD88- or CARD11-mutant B-Cell Lymphomas. Blood (2020). doi: 10.1182/blood.2020005244

13. Do P, Beckwith KA, Cheney C, Tran M, Beaver L, Griffin BG, et al. Leukemic B Cell CTLA-4 Suppresses Costimulation of T Cells. J Immunol Baltim Md 1950 (2019) 202(9):2806-16. doi: 10.4049/jimmunol.1801359

14. Guerra N, Tan YX, Joncker NT, Choy A, Gallardo F, Xiong N, et al. NKG2DDeficient Mice are Defective in Tumor Surveillance in Models of Spontaneous Malignancy. Immunity (2008) 28(4):571-80. doi: 10.1016/j.immuni.2008.02.016

15. Belting L, Hömberg N, Przewoznik M, Brenner C, Riedel T, Flatley A, et al. Critical Role of the NKG2D Receptor for NK Cell-Mediated Control and Immune Escape of B-Cell Lymphoma. Eur J Immunol (2015) 45(9):2593-601. doi: 10.1002/eji.201445375

16. Hofbauer JP, Heyder C, Denk U, Kocher T, Holler C, Trapin D, et al. Development of CLL in the TCL1 Transgenic Mouse Model Is Associated With Severe Skewing of the T-cell Compartment Homologous to Human CLL. Leukemia (2011) 25(9):1452-8. doi: 10.1038/leu.2011.111

17. Betzler AC, Theodoraki M-N, Schuler PJ, Döscher J, Laban S, Hoffmann TK, et al. NF- KB and Its Role in Checkpoint Control. Int J Mol Sci (2020) 21(11). doi: 10.3390/ijms21113949

18. Ishida Y, Agata Y, Shibahara K, Honjo T. Induced Expression of PD-1, a Novel Member of the Immunoglobulin Gene Superfamily, Upon Programmed Cell Death. EMBO J (1992) 11(11):3887-95. doi: 10.1002/ j.1460-2075.1992.tb05481.x

19. Dong H, Zhu G, Tamada K, Chen L. B7-H1, A Third Member of the B7 Family, Co-Stimulates T-Cell Proliferation and Interleukin-10 Secretion. Nat Med (1999) 5(12):1365-9. doi: 10.1038/70932

20. Freeman GJ, Long AJ, Iwai $Y$, Bourque K, Chernova T, Nishimura H, et al. Engagement of the PD-1 Immunoinhibitory Receptor by a Novel B7 Family Member Leads to Negative Regulation of Lymphocyte Activation. J Exp Med (2000) 192(7):1027-34. doi: 10.1084/jem.192.7.1027

21. Menter T, Bodmer-Haecki A, Dirnhofer S, Tzankov A. Evaluation of the Diagnostic and Prognostic Value of PDL1 Expression in Hodgkin and B-Cell Lymphomas. Hum Pathol (2016) 54:17-24. doi: 10.1016/j.humpath. 2016.03.005

22. Chen BJ, Chapuy B, Ouyang J, Sun HH, Roemer MGM, Xu ML, et al. PD-L1 Expression is Characteristic of a Subset of Aggressive B-Cell Lymphomas and
Virus-Associated Malignancies. Clin Cancer Res Off J Am Assoc Cancer Res (2013) 19(13):3462-73. doi: 10.1158/1078-0432.CCR-13-0855

23. Chen DS, Mellman I. Elements of Cancer Immunity and the Cancer-Immune Set Point. Nature (2017) 541(7637):321-30. doi: 10.1038/nature21349

24. Godfrey J, Tumuluru S, Bao R, Leukam M, Venkataraman G, Phillip J, et al. PD-L1 Gene Alterations Identify a Subset of Diffuse Large B-Cell Lymphoma Harboring a T-Cell-Inflamed Phenotype. Blood (2019) 133(21):2279-90. doi: 10.1182/blood-2018-10-879015

25. Ansell SM. Nivolumab in the Treatment of Hodgkin Lymphoma. Clin Cancer Res Off J Am Assoc Cancer Res (2017) 23(7):1623-6. doi: 10.1158/10780432.CCR-16-1387

26. Xu-Monette ZY, Zhou J, Young KH. PD-1 Expression and Clinical PD-1 Blockade in B-Cell Lymphomas. Blood (2018) 131(1):68-83. doi: 10.1182/ blood-2017-07-740993

27. Auclair H, Ouk-Martin C, Roland L, Santa P, Al Mohamad H, Faumont N, et al. EBV Latency III-Transformed B Cells Are Inducers of Conventional and Unconventional Regulatory T Cells in a PD-L1-Dependent Manner. J Immunol Baltim Md 1950 (2019) 203(6):1665-74.

28. Zhang J, Medeiros LJ, Young KH. Cancer Immunotherapy in Diffuse Large B-Cell Lymphoma. Front Oncol (2018) 8:351. doi: 10.3389/fonc.2018.00351

29. Knittel G, Liedgens P, Korovkina D, Seeger JM, Al-Baldawi Y, Al-Maarri M, et al. B-Cell-Specific Conditional Expression of Myd88p.L252P Leads to the Development of Diffuse Large B-Cell Lymphoma in Mice. Blood (2016) 127 (22):2732-41. doi: 10.1182/blood-2015-11-684183

30. Ngo VN, Young RM, Schmitz R, Jhavar S, Xiao W, Lim K-H, et al. Oncogenically Active MYD88 Mutations in Human Lymphoma. Nature (2011) 470(7332):115-9. doi: 10.1038/nature09671

31. Lenz G, Wright GW, Emre NCT, Kohlhammer H, Dave SS, Davis RE, et al. Molecular Subtypes of Diffuse Large B-Cell Lymphoma Arise by Distinct Genetic Pathways. Proc Natl Acad Sci USA (2008) 105(36):13520-5. doi: 10.1073/pnas.0804295105

32. David A, Arnaud N, Fradet M, Lascaux H, Ouk-Martin C, Gachard N, et al. c-Myc Dysregulation is a Co-Transforming Event for Nuclear Factor- $\mathrm{\kappa B}$ Activated B Cells. Haematologica (2017) 102(5):883-94. doi: 10.3324/ haematol.2016.156281

33. Bichi R, Shinton SA, Martin ES, Koval A, Calin GA, Cesari R, et al. Human Chronic Lymphocytic Leukemia Modeled in Mouse by Targeted TCL1 Expression. Proc Natl Acad Sci USA (2002) 99(10):6955-60. doi: 10.1073/ pnas. 102181599

34. Moore CR, Liu Y, Shao C, Covey LR, Morse HC, Xie P. Specific Deletion of TRAF3 in B Lymphocytes Leads to B-Lymphoma Development in Mice. Leukemia (2012) 26(5):1122-7. doi: 10.1038/leu.2011.309

35. Li Z, Wang H, Xue L, Shin D-M, Roopenian D, Xu W, et al. E $\mu$-BCL10 Mice Exhibit Constitutive Activation of Both Canonical and Noncanonical NF- $\mathrm{\kappa B}$ Pathways Generating Marginal Zone (MZ) B-Cell Expansion as a Precursor to Splenic MZ Lymphoma. Blood (2009) 114(19):4158-68. doi: 10.1182/blood2008-12-192583

36. McClanahan F, Riches JC, Miller S, Day WP, Kotsiou E, Neuberg D, et al. Mechanisms of PD-L1/PD-1-Mediated CD8 T-Cell Dysfunction in the Context of Aging-Related Immune Defects in the E $\mu$-TCL1 CLL Mouse Model. Blood (2015) 126(2):212-21. doi: 10.1182/blood-2015-02-626754

37. Marom A, Barak AF, Kramer MP, Lewinsky H, Binsky-Ehrenreich I, Cohen S, et al. CD84 Mediates CLL-Microenvironment Interactions. Oncogene (2017) 36(5):628-38. doi: 10.1038/onc.2016.238

38. Lewinsky H, Barak AF, Huber V, Kramer MP, Radomir L, Sever L, et al. CD84 Regulates PD-1/PD-L1 Expression and Function in Chronic Lymphocytic Leukemia. J Clin Invest (2018) 128(12):5465-78. doi: 10.1172/JCI96610

39. McClanahan F, Hanna B, Miller S, Clear AJ, Lichter P, Gribben JG, et al. PDL1 Checkpoint Blockade Prevents Immune Dysfunction and Leukemia Development in a Mouse Model of Chronic Lymphocytic Leukemia. Blood (2015) 126(2):203-11. doi: 10.1182/blood-2015-01-622936

40. Vincent-Fabert C, Soubeyran I, Velasco V, Parrens M, Jeannet R, Lereclus E, et al. Inflamed Phenotype of Splenic Marginal Zone B-Cell Lymphomas With Expression of PD-L1 by Intratumoral Monocytes/Macrophages and Dendritic Cells. Cell Mol Immunol (2019) 16(6):621-4. doi: 10.1038/s41423019-0228-y

41. Spina V, Rossi D. NF- $\kappa B$ Deregulation in Splenic Marginal Zone Lymphoma. Semin Cancer Biol (2016) 39:61-7. doi: 10.1016/j.semcancer.2016.08.002 
42. Vincent-Fabert C, Roland L, Zimber-Strobl U, Feuillard J, Faumont N. PreClinical Blocking of PD-L1 Molecule, Which Expression Is Down Regulated by NF-KB, JAK1/JAK2 and BTK Inhibitors, Induces Regression of Activated B-Cell Lymphoma. Cell Commun Signal CCS (2019) 17(1):89. doi: 10.1186/ s12964-019-0391-x

43. Vincent-Fabert C, Saintamand A, David A, Alizadeh M, Boyer F, Arnaud N, et al. Reproducing Indolent B-Cell Lymphoma Transformation With T-Cell Immunosuppression in LMP1/CD40-Expressing Mice. Cell Mol Immunol (2019) 16(4):412-4. doi: 10.1038/s41423-018-0197-6

44. Kleinstern G, Yan H, Hildebrandt MAT, Vijai J, Berndt SI, Ghesquières H, et al. Inherited Variants at 3q13.33 and 3p24.1 Are Associated With Risk of Diffuse Large B-Cell Lymphoma and Implicate Immune Pathways. Hum Mol Genet (2020) 29(1):70-9. doi: 10.1093/hmg/ddz228

45. Khailaie S, Rowshanravan B, Robert PA, Waters E, Halliday N, Badillo Herrera JD, et al. Characterization of CTLA4 Trafficking and Implications for Its Function. Biophys J (2018) 115(7):1330-43. doi: 10.1016/ j.bpj.2018.08.020

46. Herishanu Y, Pérez-Galán P, Liu D, Biancotto A, Pittaluga S, Vire B, et al. The Lymph Node Microenvironment Promotes B-Cell Receptor Signaling, NFkappaB Activation, and Tumor Proliferation in Chronic Lymphocytic Leukemia. Blood (2011) 117(2):563-74.

47. Herrmann A, Lahtz C, Nagao T, Song JY, Chan WC, Lee H, et al. CTLA4 Promotes Tyk2-STAT3-Dependent B-Cell Oncogenicity. Cancer Res (2017) 77(18):5118-28. doi: 10.1158/0008-5472.CAN-16-0342

48. Biram A, Davidzohn N, Shulman Z. T Cell Interactions With B Cells During Germinal Center Formation, A Three-Step Model. Immunol Rev (2019) 288 (1):37-48. doi: 10.1111/imr.12737

49. Luckheeram RV, Zhou R, Verma AD, Xia B. CD $4^{+}$T Cells: Differentiation and Functions. Clin Dev Immunol (2012) 2012:925135. doi: 10.1155/2012/ 925135

50. Riemersma SA, Jordanova ES, Schop RF, Philippo K, Looijenga LH, Schuuring E, et al. Extensive Genetic Alterations of the HLA Region, Including Homozygous Deletions of HLA Class II Genes in B-Cell Lymphomas Arising in Immune-Privileged Sites. Blood (2000) 96(10):3569-77. doi: 10.1182/blood.V96.10.3569

51. Brown PJ, Wong KK, Felce SL, Lyne L, Spearman H, Soilleux EJ, et al. FOXP1 Suppresses Immune Response Signatures and MHC Class II Expression in Activated B-Cell-Like Diffuse Large B-Cell Lymphomas. Leukemia (2016) 30 (3):605-16. doi: 10.1038/leu.2015.299

52. Cox MC, Battella S, La Scaleia R, Pelliccia S, Di Napoli A, Porzia A, et al. Tumor-Associated and Immunochemotherapy-Dependent Long-Term Alterations of the Peripheral Blood NK Cell Compartment in DLBCL Patients. Oncoimmunology (2015) 4(3):e990773. doi: 10.4161/2162402X. 2014.990773
53. Diefenbach A, Jamieson AM, Liu SD, Shastri N, Raulet DH. Ligands for the Murine NKG2D Receptor: Expression by Tumor Cells and Activation of NK Cells and Macrophages. Nat Immunol (2000) 1(2):119-26. doi: 10.1038/77793

54. Malarkannan S, Shih PP, Eden PA, Horng T, Zuberi AR, Christianson G, et al. The Molecular and Functional Characterization of a Dominant Minor H Antigen, H60. J Immunol Baltim Md 1950 (1998) 161(7):3501-9.

55. Cerwenka A, Bakker AB, McClanahan T, Wagner J, Wu J, Phillips JH, et al. Retinoic Acid Early Inducible Genes Define a Ligand Family for the Activating NKG2D Receptor in Mice. Immunity (2000) 12(6):721-7. doi: 10.1016/S10747613(00)80222-8

56. Nomura M, Zou Z, Joh T, Takihara Y, Matsuda Y, Shimada K. Genomic Structures and Characterization of Rael Family Members Encoding GPIAnchored Cell Surface Proteins and Expressed Predominantly in Embryonic Mouse Brain. J Biochem (Tokyo) (1996) 120(5):987-95. doi: 10.1093/ oxfordjournals.jbchem.a021517

57. Wu J, Song Y, Bakker AB, Bauer S, Spies T, Lanier LL, et al. An Activating Immunoreceptor Complex Formed by NKG2D and DAP10. Science (1999) 285(5428):730-2. doi: 10.1126/science.285.5428.730

58. Brenner CD, King S, Przewoznik M, Wolters I, Adam C, Bornkamm GW, et al. Requirements for Control of B-Cell Lymphoma by NK Cells. Eur J Immunol (2010) 40(2):494-504. doi: 10.1002/eji.200939937

59. Salih HR, Antropius H, Gieseke F, Lutz SZ, Kanz L, Rammensee H-G, et al. Functional Expression and Release of Ligands for the Activating Immunoreceptor NKG2D in Leukemia. Blood (2003) 102(4):1389-96. doi: 10.1182/blood-2003-01-0019

60. Hilpert J, Grosse-Hovest L, Grünebach F, Buechele C, Nuebling T, Raum T, et al. Comprehensive Analysis of NKG2D Ligand Expression and Release in Leukemia: Implications for NKG2D-Mediated NK Cell Responses. J Immunol Baltim Md 1950 (2012) 189(3):1360-71. doi: 10.4049/jimmunol.1200796

61. Groh V, Wu J, Yee C, Spies T. Tumour-Derived Soluble MIC Ligands Impair Expression of NKG2D and T-Cell Activation. Nature (2002) 419(6908):734 -8. doi: $10.1038 /$ nature01112

Conflict of Interest: The authors declare that the research was conducted in the absence of any commercial or financial relationships that could be construed as a potential conflict of interest.

Copyright (c) 2021 Lemasson, Akil, Feuillard and Vincent-Fabert. This is an openaccess article distributed under the terms of the Creative Commons Attribution License (CC BY). The use, distribution or reproduction in other forums is permitted, provided the original author(s) and the copyright owner(s) are credited and that the original publication in this journal is cited, in accordance with accepted academic practice. No use, distribution or reproduction is permitted which does not comply with these terms. 